\title{
How (Not) To Think About the Sense of 'Able' Relevant to Free Will
}

Simon Kittle

Forthcoming in Inquiry.

School of Philosophy, Religion and History of Science, University of Leeds

simon@simonkittle.com

The School of Philosophy, Religion and History of Science

University of Leeds

Leeds

LS2 9JT

This is the submitted version of this paper.

Published version: https://www.tandfonline.com/doi/full/10.1080/0020174X.2021.1904645

Please cite the published version. 


\section{How (Not) To Think About the Sense of 'Able' Relevant to Free Will}

Abstract:

This essay is an investigation into the sense of 'able' relevant to free will, where free will is understood as requiring the ability to do otherwise. I argue that van Inwagen's recent functional specification of the relevant sense of 'able' is flawed, and that explicating the powers involved in free will shall likely require paying detailed attention to the semantics and pragmatics of 'can' and 'able'. Further, I argue that van Inwagen's promise-level ability requirement on free will is too strong. I also argue that Mele's conjecture that the strength of the ability to perform the 'alternative' action (i.e. to refrain, to decide otherwise) be no higher than the strength of the ability exercised in performing an action is mistaken. I suggest there is an asymmetry in the strengths of the abilities which make up the n-way power that comprises free will, and that this looks to have some interesting consequences for the connection between the abilities required for free will and, e.g., the 'up to us' locution.

Keywords: free will, ability, moral responsibility, able, can

The writing of this publication was partially supported by a grant from the John Templeton Foundation, God and the Book of Nature [Grant ID. 61507]. The opinions expressed in this publication are those of the author(s) and do not necessarily reflect the view of the John Templeton Foundation.

\section{Introduction}

On one traditional understanding free will requires the ability to do otherwise such that, if a person, $\mathrm{P}$, is to have free will with respect to some action $X$ it must be the case, sometime before the agent $\mathrm{X}-\mathrm{s}$, that the statement

\section{(1) P is able to $X$}

is true and at least one statement of the following form is true (where $Y$ is not the same as $X$ ):

(2) $\mathrm{P}$ is able to $Y$

In (2), the placeholder $Y$ must be replaced with an action distinct from that which $X$ is replaced with, though $Y$ may simply be refrain from $X$-ing. The minimal case is where the agent has two courses of action available, but the agent may have more than two. For this reason we can say that free will is an 'n-way power with respect to the future' (van Inwagen 2017, 220; cf. Steward 2012, 126, 131).

The 'is able to' in these statements expresses the concept of having something within one's power, a concept which may also be expressed with one of the ordinary meanings of 'can', such that the following are all roughly equivalent:

I can attend the meeting

I am able to attend the meeting

It is within my power to attend the meeting 
According to van Inwagen (2017, 210-215), from the 1960s to the mid-1980s most philosophers agreed that this was how to understand free will. And the central problems concerning free will were understood to be: (Q1) Is free will compatible with causal determinism? and (Q2) Is free will compatible with indeterminism? At some point in the mid-1970s, Harry Frankfurt's essay 'Moral Responsibility and Alternate Possibilities' (1969) began to be well-known. In that essay, Frankfurt put forward a series of cases where agents were supposedly morally responsible despite not being able to do otherwise. These cases were widely accepted, and those who accepted them either: (i) rejected the idea that moral responsibility requires free will, and so lost interest in questions (Q1) and (Q2), or (ii) redefined 'free will' as the control required for moral responsibility, and so lost interest in questions $(\mathrm{Q} 1)$ and $(\mathrm{Q} 2)$.

For those who, like van Inwagen, reject Frankfurt's conclusion, the primary problems concerning free will remain $(\mathrm{Q} 1)$ and $(\mathrm{Q} 2)$, with the possible addition of $(\mathrm{Q} 3)$ : Where does Frankfurt's argument go wrong? ${ }^{1}$ Answering any of these questions will involve a consideration of the kind of abilities ascribed to agents by statements with the form found in (1) and (2). One natural way to investigate these abilities is to consider the meaning of the English terms 'can' or 'able', and in a recent essay van Inwagen pursues this project. His aim is to argue that the 'sense of 'able" relevant to free will is connected to an agent's ability to promise to do something.

The main purpose of this essay (sections 2-4) is to suggest that, when investigating free will by considering terms such as 'can' or 'able', careful attention must be paid to the semantics and pragmatics of these terms. I argue for this primarily through a discussion of van Inwagen's recent discussion of the 'sense of 'able" relevant to free will. Van Inwagen attempts to functionally define the relevant sense of 'able' while saying very little about the semantics or pragmatics of 'able'. Functionally specifying the relevant sense of 'able' may be desirable, since it would enable identification in the absence of an analysis/account of 'able', but it also risks making the task of identifying the relevant sense of 'able' more difficult, because it precludes using - since it ignores - the insights developed by linguists into how 'able' works and the kind of properties it can be used to ascribe. Throughout this discussion, various points are made about the nature of abilities. I round off the essay (in section 5) with a consideration of another of van Inwagen's claims, namely, that an agent can freely perform some action $A$ only if the agent is able to promise to perform that action. I argue that this is false and suggest that the agent does need to be able to refrain from $A$-ing with a very high degree of reliability to be responsible for $A$-ing. This points towards an asymmetry in the senses of 'able' relevant to free will: the sense in which an agent needs to be able to perform the action for which they will be responsible differs along at least one dimension from the sense in which the agent needs to be able to avoid performing the action.

\section{Van Inwagen on 'the sense of 'able' relevant to free will'}

\footnotetext{
${ }^{1}$ Cf. van Inwagen $(2017,220)$.
} 
According to van Inwagen, 'the meaning of the word 'able' as this word was used in the discussions of the problem of free will in the classical era [mid 1960s - mid 1980s]' - and, though he does not say so explicitly, the meaning of 'able' that we should be interested in, because the classical era had it right - is 'best explained in connection with a certain way in which promises can be defective' (van Inwagen 2017, 221). The certain way promises can be defective which helps us to get a handle on the relevant sense of 'able' is captured by the following:

$\mathbf{T}^{\prime}$. A promise is necessarily defective if the person making the promise does not believe that (does not have the belief that) he or she is able to keep it (van Inwagen 2017, 224).

Put otherwise: some promises are defective precisely because the agent does not believe she is able to keep the promise. Now, we can't simply say that the sense of 'able' relevant to free will is that sense of 'able' alluded to in $\mathbf{T}$ ' because there are multiple senses of 'able' which would make a promise defective in this way. The following example from van Inwagen $(2017,224)$ illustrates this:

(Grigory) Grigory Sokolov is able to play Chopin's Prelude in E Minor even when no piano is available to him, and there's a stronger sense in which he's able to play that difficult work only when he has access to a piano.

This example employs two senses of 'able'. The first is often called 'general ability' or 'skill'. The second sense of 'able' might intuitively be thought of as 'general ability plus opportunity'; it seems to require that Grigory's circumstances be a certain way, such that he has the opportunity to use his skill. Call this second sense the non-general sense of 'able'. We might regiment these two senses as follows:

(3) In view of his skill, Sokolov is able to play the piano.

(4) In view of his skill and his currently having access to a piano, Sokolov is able to play the piano.

Statement (3) expresses the general sense: it abstracts away from everything except Sokolov's skill and so could be true of Sokolov even when there is no piano nearby. Statement (4) expresses some sort of non-general sense of 'able', i.e., 'general ability plus some notion of opportunity' sense: it takes into account not just Sokolov's skill but also his having access to a piano. Clearly these are different senses of 'able' because (3) might be true at a time when (4) is not. But - and this is the key point here - if Sokolov did not believe that he was able in either the general (3) or non-general (4) sense to play the piano, that would suffice to make a promise to play defective. So the criterion in $\mathbf{T}^{\prime}$ picks out both (3) and (4) and therefore the sense of 'able' relevant to free will cannot be identified with the sense picked out by $\mathbf{T}^{\prime}$. Neither can we say that each of the senses $\mathbf{T}^{\prime}$ identifies is (equally?) relevant. The lack of a belief that one is able in the general sense to $A$ suffices to make a promise to $A$ defective. But the presence of a general ability (and the accompanying belief 
that one is able in this sense) is not sufficient for free will. ${ }^{2}$ So we need some further criterion to identify the sense we are interested in. Van Inwagen proposes the following: ${ }^{3}$

The Relevant Sense. Someone is able in the Relevant Sense (is 'able $R S$ ') to do something just in the case that that person is able to do that thing in the strongest sense of 'able' such that, if one made a promise and did not believe that (did not have the belief that) one was able (in that sense) to keep that promise, that promise would be defective (van Inwagen 2017, 225).

This says that the sense of 'able' relevant to free will is the strongest sense of those picked out by $\mathbf{T}$ '. The idea seems to be that for any given action, the promise-criterion in $\mathbf{T}^{\prime}$ can be understood as determining a set of senses of 'able'. This set has more than one member, and the members are not equally relevant to free will, so we need to pick. And what we do is to pick the strongest, where 'stronger' is defined as follows:

Stronger. If $x$ and $y$ are two senses of 'able', $x$ is stronger than $y$ just in the case that (i) if someone is able to do something in sense $x$, then, necessarily, that person is able to do that thing in sense $y$, and (ii) it is possible for there to be someone who is able to do something in sense $y$ but is not able to do that thing in sense $x$ (van Inwagen 2017, 225).

Let's apply this 'stronger than' test to the Grigory example. According to van Inwagen, if Sokolov is able to play the piano given his skill and his having access to a piano (i.e. in sense (4)), it necessarily follows that Sokolov can play the piano given his skill (i.e. in sense (3)). But the converse is not true. So the second sense of 'able' in van Inwagen's Grigory example (implying the presence of some sort of opportunity) is stronger than the first (which is something like the skill sense of 'able').

Finding examples which fit this pattern is not difficult: there is a sense of 'able' in which David is able to bake a Key Lime Pie even when he's not in the kitchen (skill), and there's a stronger sense in which he's able to bake a Key Lime Pie only when he has access to an oven (skill plus opportunity); there's a sense of 'able' in which Thea is able to give a tour of Berlin even when she's not in Berlin (she has the knowledge), and there's a stronger sense in which she's able to give a tour when she is in Berlin (she has the knowledge and opportunity). Given our interest is free will, it's clear that in each case it will be the second sense we're interested in, a result van Inwagen's functional specification affirms. And presumably the thought is that we could repeat the procedure above comparing all the senses of 'able' picked out by $\mathbf{T}^{\prime}$ pairwise until we arrived at the strongest.

Van Inwagen's procedure for functionally specifying the sense of 'able' relevant to free will has the virtue of not relying on any analysis or account of 'able' (or of the concepts expressed

\footnotetext{
${ }^{2}$ This is agreed upon by (almost all) compatibilists and incompatibilists who think that free will requires the ability to do otherwise (see, as representative, (Vihvelin 2013, 15) and (van Inwagen 1983, 10)). Some of those who do not think free will requires the ability to do otherwise disagree. But my purpose in this section is not to argue against such thinkers, but to assess van Inwagen's project on its own terms.

3 That van Inwagen provides a further test, rather than simply suggesting it is the 'ability plus opportunity' sense, suggests that he believes there are more senses of 'able' than those so-far outlined.
} 
in a context by that term), which is of course the point, since both are complex, contested topics. In the following section, however, I will argue that van Inwagen's functional specification of 'able' fails precisely because insufficient attention has been paid to the nature of the modal claims made by ability ascriptions.

\section{On discussions about 'the sense of 'able' relevant to free will'}

In the previous section, I followed van Inwagen in employing the phrase 'the sense of 'able' relevant to free will' without giving much attention to that locution. In this section I will suggest that the phrase 'the sense of 'able', latches onto its proper target (given our interest in free will) only if, either 'sense' is used with its ordinary, everyday meaning, or 'sense' is used to mean semantic value and some substantial assumptions about the semantics of 'can'/'able' are made. Crucially, the clause 'the sense of 'able' relevant to free will' doesn't latch onto the correct target if 'sense' means semantic value and the standard semantics of 'can' are assumed.

One assumption I make in what follows should be noted: in semantics, more work has been done on the semantics of 'can' than has been done on 'able'. Part of the reason for this seems to be a prevailing assumption that much of the work on 'can' will transfer over to 'able'. That assumption seems reasonable, ${ }^{4}$ so going forward I will focus on the semantics of 'can' and 'could have' on which lots has been written.

To see the kinds of confusion that can arise from the various understandings of the 'sense of 'able'/'can', consider the following scene drawn from Jonathan Franzen's novel Freedom (2011, 57): Patty has just discovered that her best-friend Eliza is 'partying' with Carter (in whom Patty has a romantic interest) and a further unnamed female. Eliza went to the 'party' on the understanding it was a large gathering; when she arrives, Eliza learns that Carter only invited her because the unnamed female wouldn't have come if it were just her and Carter. Eliza, despite knowing of Patty's interest in Carter, decides to stay and join the fun. When Patty learns of this, she is upset, and feels that Eliza has been disloyal, having helped to facilitate Carter's getting close to someone else. Eliza complains that she didn't initially know of Carter's motives, at which point Patty states bluntly: 'You could have left'.

As I'm interpreting this scene, ${ }^{5}$ Patty, with her utterance of 'You could have left', is underscoring the reasonableness of her being upset at Eliza. In pointing out that Eliza could have left the party, Patty is employing a common shorthand way of emphasising that Eliza had a choice about staying. In doing so, Patty is implicitly appealing to free will as involving the ability to do otherwise to justify her blaming Eliza. Patty, on this reading, is ascribing to Eliza the kind of power we're interested in. Given the example so interpreted, the need to pay attention to the semantics and pragmatics of 'can' in discussions of free will can be illustrated by considering the following propositions:

\footnotetext{
${ }^{4}$ The difficulty of finding an utterance involving 'able' which cannot be paraphrased using 'can' provides some support for a close connection here.

${ }^{5}$ My purpose is not Franzenian exegesis, so it suffices for my purposes to provide one plausible interpretation of the scene.
} 
(6) (What is said - minimalism) Eliza could have left

(7) (What is said - speaker) Eliza could have left the party

(8) (What is implicated \#1) Eliza was wrong to stay at the party

(9) (What is implicated \#2) Eliza is to blame for staying at the party

My contention is that when we are interested in questions (Q1) through (Q3), we should be interested in the truth-conditions of (7). Proposition (7) is arguably the literal content of the most basic proposition that Patty intends to express when she utters 'You could have left' and it ascribes the kind of power that is relevant to free will.

It is controversial, however, whether (7) is the literal content of the most basic proposition expressed: some semantic minimalists might say that (6) is the literal content of what is said, and it is not clear whether (6) also ascribes the kind of power relevant to free will. It is also controversial what determines the truth-conditions of (7). I take it that in everyday, nontechnical usage, 'sense' is used to pick out the concept that a term is used to express when used on a given occasion or context. When used in this everyday way, 'sense' encompasses the semantics of the term and also any pragmatic processes that might be required to furnish a complete proposition (if such there be). As a result, with 'sense' taken in the everyday sense, the question 'What is the sense of 'able' relevant to free will?' will find its target.

Suppose, however, we understand 'sense' to mean 'semantic value' (defined as that component of meaning which is invariant across all uses) and we assume with many (the majority of?) contemporary semanticists that 'can' is univocal but systematically contextdependent with pragmatic processes operating on the context (including the speaker's intentions) to determine the content of the proposition expressed by a given utterance. Angelika Kratzer's account of 'can' is one such view. It posits two contextual parameters for 'can', the modal base and the ordering source, both of which take the context as a parameter in such a way that the truth-conditions of the proposition expressed are determined in part by pragmatics. Anna Papafragou's summary of this view is helpful:

The sort of modal base and ordering source that is appropriate for the interpretation of individual modal words is generally determined pragmatically (modulo certain lexically specified restrictions on admissible conversational backgrounds). Hence modal expressions are treated as context-dependent and vague, rather than lexically ambiguous items. ... [I]t seems that two of the three components of modality in Kratzer's proposal, namely the conversational background [i.e. the modal base] and the ordering source, involve non-linguistic knowledge and consequently belong to pragmatics (Papafragou 2000, 33).

If, therefore, 'sense' means 'semantic value', and a Kratzerian-type semantics is correct such that the precise kind of modality expressed by an utterance of 'can' is determined by pragmatic processes, then answering the question 'What is the sense of 'able' relevant to free will?' will not yield an answer to our original question. 
This point is not in itself a problem for van Inwagen's thesis. But it poses an obstacle to clear discussion thereof because, as we will see below, to understand where van Inwagen's functional specification fails we must look at the details of the semantics of 'can'/'able'; that is, we need to consider the sense qua semantic value of 'can'/'able' while remembering that our target is the everyday sense of 'can'/'able'.

One additional point is worth mentioning. The truth-conditional content of what the speaker intends to say with an utterance involving 'can' is, on Kratzer-style views, determined in part by pragmatic processes. But the processes in question are not ones of Gricean implicature. Patty, when she utters (5), might very well implicate the propositions (8) and (9). On the Gricean model, the hearer takes what is said and the context and then infers that the speaker wanted to communicate (8) and (9). However, for accounts of 'can' where pragmatic processes play a part in determining the truth-conditions of (7), it is likely not Gricean inferences that the account appeals to, but processes such as free enrichment. This is worth noting because sometimes the phrase 'the use of an utterance' is used exclusively for Gricean implicatures, and therefore, just as the phrase 'the sense of 'able'" does not necessarily latch onto our target, neither does the phrase 'the use of 'able' in that utterance'.

Given that van Inwagen's goal is to functionally specify 'the relevant sense of 'able' because 'he has no analytic definition to give' (van Inwagen 2017, 226), it seems likely that he was using 'sense' with its everyday meaning and assuming that the jump to utterance truthconditions was unproblematic. In what follows I will make this move explicit by referring to the everyday sense or the e-sense of 'able'.

\section{On functionally specifying 'the relevant sense of 'able",}

Van Inwagen's functional specification of the relevant everyday sense of 'able' involves two steps: first we fix a set of everyday senses of 'able' (using the criterion to do with promising), then we use the stronger than test to pick out the everyday sense - the $e$-sense - which is relevant to free will. In a footnote, van Inwagen considers the following worry: suppose that 'there are two senses of 'able' that satisfy the condition vis-à-vis promising laid down in the definition, that no stronger sense of 'able' [also satisfies that condition], and that neither sense is stronger than the other (perhaps the two senses are equivalent; or perhaps they are simply "incommensurable": they are not equivalent but neither is stronger than the other)?' (van Inwagen 2017, 225 fn. 31). And van Inwagen's reply is: 'I'll cross that bridge if I come to it - that is, if someone presents a plausible example of two such cases'.

I begin by building two such proverbial bridges. The first is a modification of one of van Inwagen's own examples:

(Grigory and Grigory) Grigory Sokolov is able to play Chopin's Prelude in E Minor even when no piano is available to him; there's a stronger e-sense in which he's able to play that difficult work only when he has access to a piano; and an even stronger esense in which he's able to play that work in front of an audience of top dignitaries. 
Grigory Novak, a professional weightlifter, was also (we will suppose) able to play Chopin's Prelude in E Minor. Being only an amateur pianist, he couldn't play it onetenth as well as Sokolov (who could?), but he could play it nonetheless, and he did have an interesting party piece: he could play Chopin's Prelude in E Minor with a $5 \mathrm{~kg}$ weight tied to each arm. This is something that not even Grigory Sokolov could do; but each had their expertise: Novak couldn't play the piece in front of top dignitaries.

I contend that this example refutes the idea that van Inwagen's stronger-than test can be applied to any two e-senses of 'able'. Here's why. If both Grigorys were on a stage in front of a piano with an audience of dignitaries, Sokolov would be able to play Chopin's Prelude in E Minor, but Novak would not. Let's call this the dignitary e-sense of 'able', or 'able $\mathrm{d}$ '. By contrast, if both Grigorys were in front of a piano with no audience, and each had $5 \mathrm{~kg}$ weights attached to both of his arms, Novak would be able to play, but Sokolov would not. Let's call this the weight e-sense of 'able', or 'able $\mathrm{w}_{\mathrm{w}}$ '. The problem for van Inwagen is that neither of these everyday senses is stronger than the other. Being able ${ }_{\mathrm{d}}$ to play Chopin's Prelude in E Minor doesn't entail being able ${ }_{\mathrm{w}}$ to play Chopin's Prelude in E Minor. Being able $_{w}$ to play Chopin's Prelude in E Minor doesn't entail being able $e_{d}$ to play Chopin's Prelude in E Minor. But if neither able ${ }_{\mathrm{d}}$ nor able ${ }_{\mathrm{w}}$ is stronger than the other, van Inwagen's procedure for identifying the strongest e-sense fails.

It might be objected that the failure of van Inwagen's functional specification doesn't yet follow. For while it might be conceded that neither 'able ${ }_{\mathrm{d}}$ ' nor 'able ${ }_{\mathrm{w}}$ ' is stronger than the other, it might be suggested that there is a further e-sense of 'able' which is stronger than them both, such that van Inwagen's test still yields the strongest e-sense of 'able'.

This rejoinder, however, relies on a contingent feature of the Grigory and Grigory case, namely, that being in front of dignitaries and having $5 \mathrm{~kg}$ weights on one's arms are independent conditions that may (or may not) affect one's ability to play Chopin's Prelude in E Minor. Because they are independent conditions, it is possible that someone might be able to overcome both these obstacles: someone might be 'able ${ }_{\mathrm{dw}}$ ' to play Chopin's Prelude, such that they can play it when in front of dignitaries with $5 \mathrm{~kg}$ weights on their arms. That everyday sense of 'able' would be stronger than both 'abled' and 'able ${ }_{\mathrm{w}}$ ', and that, it might be thought, should cast doubt on the claim that there is no strongest e-sense. But because the rejoinder derives from a contingent feature of the case, we can develop cases which make such a reply impossible. Here is one such case - a second bridge for van Inwagen to cross:

(Mary and Marty) Mary can memorise a shuffled pack of cards, but only if she's listening to heavy metal music (and nothing else), which she uses to create a 'memory palace' to aid her; Marty can memorise a shuffled pack of cards, but only if he's listening to classical music (and nothing else), which he uses to create a 'memory palace' to aid him. Neither can perform the feat of memorisation in silence, nor while listening to multiple kinds of music at once.

Let's call being able to memorise with just heavy metal music playing 'able $\mathrm{m}_{\mathrm{m}}$ and being able to memorise with just classical music playing 'able' ${ }_{\mathrm{c}}$. As with the previous example, being 
able $_{\mathrm{m}}$ to memorise doesn't entail one is able $\mathrm{e}_{\mathrm{c}}$ to memorise; and being able $\mathrm{e}_{\mathrm{c}}$ to memorise doesn't entail one is able $\mathrm{m}_{\mathrm{m}}$ to memorise. So neither everyday sense of 'able' is stronger than the other.

Moreover, far from being obstacles to overcome, the music facilitates the memorisation. And it is this feature which rules out the necessary existence of an everyday sense of 'able' stronger than both 'able ${ }_{\mathrm{c}}$ ' and 'able $\mathrm{m}$ '. Suppose there is someone, call him Maurice, who can memorise a shuffled pack of cards when there is both heavy metal music and classical music playing - he is able $e_{c m}$ to memorise the cards. It by no means follows that Maurice could memorise the cards if there were only heavy metal music playing or if there were only classical music playing. The playing of heavy metal music and classical music at the same time is not additive in the same way that being in front of dignitaries and having weights attached to one's arms might be thought to be. The two kinds of music being played together form a new kind of sound, perhaps something like white noise, which might allow Maurice to zone out. And it might well be that someone who can memorise with white noise (or similar) in the background can't memorise if there is just a single type of music playing because that might be too distracting. But this means that 'able $\mathrm{cm}_{\mathrm{m}}$ ' isn't stronger than 'able ${ }_{\mathrm{c}}$, nor stronger than 'able $\mathrm{m}_{\mathrm{m}}$, and neither is 'able $\mathrm{c}_{\mathrm{c}}$ ' stronger than 'able $\mathrm{m}_{\mathrm{m}}$ ' nor vice versa. So we have two esenses of able - 'able' and 'able $e_{\mathrm{m}}$ ' - neither of which is stronger than another, and for which we have at least some reason to think there is likely no e-sense of 'able' stronger than both. I conclude, therefore, that van Inwagen's stronger than test fails.

Objection: the Mary and Marty example presupposes a description of the abilities which van Inwagen would do well to reject, namely, a description of the situation according to which listening to heavy metal music enters into the definition of the ability. But van Inwagen - or someone endorsing his functional specification of the relevant sense of 'able' should reject that. Such a theorist should claim that there is a single ability to memorise a shuffled pack of cards (or similar) and that the differences between Mary, Marty and Maurice concern when they possess, or when they are able to exercise, that ability to memorise.

Reply: the objector is attempting to argue that there is only one e-sense of 'able' in question, thus precluding the alleged failure of the stronger-than test. But this objection would be fatal to van Inwagen's project, since it precludes from consideration those everyday senses of 'able' which are our target. That is, our interest is in the truth-conditions of literal propositions expressed by utterances asserting that some agent is able to do something in some given situation. Such propositions reflect what agents can or are able to do given their (general) abilities and the opportunities they do (or don't) possess. That is, it's the e-senses of 'able' that include the attribution of opportunities which we are interested in - a point with which van Inwagen would agree (See e.g. van Inwagen 1983, 11). But the objection above only succeeds if those are excluded from view (since it is those which cannot be compared). Thus, if the objection were to succeed in rescuing van Inwagen's procedure, it would do so at the cost of guaranteeing the procedure produces the wrong result.

I have shown that the stronger-than test proposed by van Inwagen fails. But can we say why it fails? We can, if we consider the semantics in more detail. One idea common to many 
contemporary semantic accounts of 'can' (and 'able') is that it expresses a form of relative modality. On Kratzer's account, a sentence such as 'S can A' can be informally regimented as follows:

In view of $X_{1}, X_{2} \ldots X_{n}, S$ can $A$

The propositions $\mathrm{X}_{1} \ldots \mathrm{X}_{\mathrm{n}}$ constitute what Kratzer terms the conversational background of the claim expressed by 'can'. These propositions determine the kind of relative modality in question. For epistemic modals, the propositions $X_{1} \ldots X_{n}$ would include some of the contents of a person's beliefs or knowledge; for deontic modals, they might be the country's laws, social conventions, or a moral system; for abilities, they will be some of the facts about the agent which ground the ability. Semanticists tend to group modals into classes such as epistemic, deontic, and root, but it's important to note these are only broad classes, and the determinate kind of relative modality of any given utterance is determined either by an explicit 'In view of...' clause (as in semanticists' and philosophers' examples) or by the contextual details (in most real-world cases), each of which fixes the conversational background of a given utterance.

Kratzer (1977) proposed to analyse statements of the above form in terms of 'possibility that' with that locution interpreted as the sentential possibility operator of modal logic:

In view of $\mathrm{X}_{1}, \mathrm{X}_{2} \ldots \mathrm{X}_{\mathrm{n}}$, it is possible that $\mathrm{S} A-\mathrm{s}$

It is crucial to see, however, that this further step is not mandated by the idea that 'can'/'able' express claims about relative modality. This is important not least because Anthony Kenny (1975) presented a powerful objection against the claim that the 'can' of ability can be analysed using a single sentential possibility operator of modal logic - an objection endorsed by van Inwagen $(2017,213)$. Kenny's argument does not, however, refute the general idea that 'can'/'able' express claims about relative modality and several extant accounts exist which, by employing multiple operators, attempt to avoid Kenny's objection (see e.g. Brown 1988, Hackl 1998, Horty 2001).

If 'can' and 'able' express claims about relative modality, and if the type of modality is determined in part by contextual factors dependent on the speaker's intention (as it is on Kratzer-style accounts), then it should be clear why van Inwagen's stronger-than test fails. The e-senses of 'able' from Grigory example illustrate the point:

'able $\mathrm{d}_{\mathrm{d}}$ : In view of his skill and his being in front of dignitaries, Grigory can play Chopin's Prelude

'able ${ }_{\mathrm{w}}$ ': In view of his skill and his having $5 \mathrm{~kg}$ weights on his arms, Grigory can play Chopin's Prelude

Both of these everyday senses of 'able' are abstractions, saying what Grigory can do relative only to some set of propositions which do not completely describe Grigory's situation. For any two e-senses of 'able', the two sets of facts in question might be different (as they are here), and in that case they may well be evaluated by considering different sets of possible 
worlds. In such cases, there will be no guarantee that one set is a proper subset of the other and this precludes it being the case that, for any two e-senses, one will always entail the other.

I want to suggest that much progress will be made on the questions (Q1)-(Q3) when more attention is paid to the fine details of how 'able' works. I conjecture that, contrary to the dominant view (see e.g. Kratzer 2012, 33, 55; Portner 2009, 201; Vetter 2015, 68), the accessibility relation (determined by, on Kratzer's terminology, the modal base and the ordering source), will not necessarily be realistic. That is, the worlds relevant to assessment of ability ascriptions will not necessarily contain the actual world. ${ }^{6}$ In addition to 'propositions expressing [the agent's] physical attributes, learned skills, and so forth' (Portner $2009,201)$, the modal base or the ordering source will contain propositions describing the environment in which the action is performed, because when ascribing abilities our concern is almost always - perhaps even just, always - whether it can be performed in a certain type of situation (and not just in some situation or other). Think about how, for example, 'is able to slalom' narrows the range of salient circumstances as compared with 'is able to ski' (and how both would usually be understood as excluding circumstances that could, in theory, be skied down), or how being able to speak in public is not usually assessed by considering those situations where someone tells a story to a group of friends, even though the latter might be a case of speaking in a public place.

A further conjecture: there is a class of e-senses of 'able' which require that the environmental circumstances in the modal base obtain, and there is another class of e-senses which make no claim about whether the environmental circumstances in the modal base obtain. The former class of e-senses typically ${ }^{7}$ ascribe a general ability and an opportunity. The relative modality of such e-senses can be informally regimented using Kratzer's 'In view of ...' phrase, as above. The latter class of e-senses ascribe only a general ability and make no claim about the obtaining of the environmental circumstances. The informal regimentation of such e-senses would be better expressed by enclosing such environmental circumstances in a clause such as 'On the assumption that...', resulting in an informal regimentation of general abilities of something like 'In view of ... [certain of the agent's intrinsic properties]... and on the assumption that ... [certain environmental conditions hold]...'. This is because the 'On the assumption that...' clause does not suggest (as the 'In view of...' phrase does) that the conditions obtain in the actual world (see my Kittle n.d.). If this is correct, there are in fact two distinctions that must be accounted for: a general/specific distinction which concerns the range of circumstances to which an ability ascription applies (circumstances which contribute to the modal base and/or ordering source, and so partly determine the kind of relative modality in question), and a general/particular

\footnotetext{
${ }^{6}$ Kratzer $(1981,61)$ notes that in German some ability statements might appeal to "normal standards" but doesn't comment on what happens if the modal requires such standards but the agent isn't currently subject to them. Nor does she explore the possibility that the inclusion of some set of "normal circumstances" in the modal base/ordering source might be a feature of all ability ascriptions.

${ }^{7}$ Only typically, because in rare cases 'able' is used to ascribe opportunities alone without any corresponding intrinsic ability; example: 'Jonas is able to apply for a British passport' might be true of Jonas because he is a British citizen, even if he is, say, in a coma and can't fill out the necessary forms, etc.
} 
distinction which concerns whether the proposition expressed affirms that the agent currently has an opportunity to exercise the general (non-particular) ability being ascribed. I have presented an account of abilities along these lines in (Kittle 2015). The primary point I wish to make here, however, is just that if 'can'/'able' express some form of relative modality, then the less attention that is paid to the semantics/pragmatics of 'can'/'able', the more difficult functionally specifying the relevant e-sense of 'can' is likely to be.

\section{Does free will require promise-level ability?}

The second aspect of van Inwagen's functional specification of the e-sense of 'able' relevant to free will ties the relevant sense to an ability to promise. The following example, inspired by one of Robert Kane's $(1996,55)$ cases, suggests that this connection does not hold:

(Ron) Ron is hospital recovering after being attacked by his archenemy. He's suffering partial paralysis in his limbs. Sometimes when he tries to use his right hand he succeeds, other times not. Suppose that it is an indeterministic matter whether, when Ron tries to move his arm, he will succeed. The odds of success are around $10 \%$.

It's clear that Ron cannot promise to move his arm. He can promise to try to move his arm, but that's beside the point. He can't promise to move his arm or anything which can only be done only by moving his arm, such as striking his enemy dead. Now suppose that Ron's archenemy visits the hospital to taunt him. While his archenemy leans over Ron's bed to deliver a jibe that would make any Bond-villain proud, Ron decides to try to strike his enemy and - much to his own surprise - he succeeds in delivering such a blow that his enemy drops down dead.

I contend that Ron is responsible for killing his enemy. Reasoning backwards, Ron was able to kill his enemy in whatever everyday sense of 'able' is required for free will, despite not having been able to promise to kill his enemy. Ron was able to promise to try to kill his enemy, of course; but what we're interested in are the abilities which ground Ron's responsibility, not just for trying to kill his enemy, but for actually doing so. As such, if Ron is indeed responsible, then the e-sense of 'able' relevant to free will comes apart from the esense relevant to promising. This was already noted by Mele in 2003. Mele suggested that even if an agent is intentionally able to $A$ - indeed, even if an agent is able to $A$ with a $98 \%$ reliability under normal circumstances - still, the agent may not be in a position to promise to do $A$, especially if the $2 \%$ of failures arise from internal factors (e.g. tiny muscle spasms / rogue neuron firings leading to lost control) (Mele 2003, 466-67). Promising, in other words, sets an incredibly high bar of success. But, Mele continued, even if such an agent cannot promise to $A$, because of the $2 \%$ chance of failure arising from internal factors, we would at the very least 'need to think hard about what implications this lack of promise-ability would have' for the agent's free will, if any (Mele 2003, 467).

Mele then put forward the following conjecture: 
If an agent's freely A-ing at $\mathrm{t}$ requires his being able at $\mathrm{t}$ to perform an action that is an alternative to A, the level of the required "alternative" ability is no higher than the highest-level ability to A required for his freely A-ing (Mele 2003, 467).

I want to suggest that examples like Ron give the lie, not just to van Inwagen's claim that promise-level ability is required for free will, but also to Mele's conjecture which concerns the asymmetry of the reliability (or 'level') of the powers which make up the agent's n-way power.

In terms of reliability, the everyday sense in which Ron is able to strike and kill his enemy is very weak: he has a $10 \%$ chance of moving his arm if he tries, much less of succeeding in striking and killing someone, let's say it's 4\%. The following two statements are true of Ron and it is the truth of these two statements which explain why it is correct to say that Ron freely kills his archenemy and is responsible for doing so: ${ }^{8}$

(10) Ron is able with $4 \%$ reliability to strike and kill an enemy standing over him.

(11) Ron is able with a very high degree of reliability to refrain from striking his enemy.

It is also true that Ron has the following ability:

(12) Ron is able with a very high degree of reliability to try to strike and kill his enemy.

But van Inwagen's claim is that free will with respect to $A$-ing requires that the agent be in a position, not just to try to $A$, but to actually $A$. So in Ron's case it is (10) and not (12) that is relevant to this claim. Similarly for Mele's conjecture. Mele's conjecture says that the reliability of the ability which would have given rise to the alternative action (in Ron's case, his refraining) can be no higher than the 'highest-level ability to $A$ required for his freely Aing'. Thus, if all that is required for Ron's freely striking and killing his archenemy is that he be able with reliability of $4 \%$ to strike and kill, then Mele's conjecture would have it that Ron's being able to refrain from striking not be more reliable than $4 \%$.

Pace Mele, my claim is that the ability to perform the 'alternative' action always needs to be of a very high reliability. This thought derives from - and does justice to - one of the intuitions which leads people to endorse the Principle of Alternative Possibilities: the intuition that to be blameworthy for $A$-ing an agent must have been able to ensure that they could have been blameless, i.e., that an agent must have been able (with very high degree of reliability) to do something which would have guaranteed them being off the hook (see Moya 2011, 11).

This requirement - i.e. that the e-sense in which someone needs to be able to perform the 'alternative' action always requires a very high reliability - also does justice to the idea that the alternative possibility the agent needs to have access to must be robust. John Martin

\footnotetext{
${ }^{8}$ I'm assuming here that any relevant doxastic/epistemic requirements on freedom and responsibility are met.
} 
Fischer (1994) introduced the idea of robustness into the discussion of Frankfurt-style cases. He pointed out that some defences of the Principle of Alternative Possibilities relied on alternative possible unfoldings of the universe which did not appear to be robust or substantial enough to ground the agent's responsibility. Most philosophers since have accepted that there is some sort of robustness criterion on the relevant alternative possibilities, although there has been much debate over the precise form that criterion should take, and whether it is fulfilled in particular cases (cf. Widerker 2006; Pereboom 2009; Moya 2011). I have defended a theory of robustness in depth in (Kittle 2018).

My point here is twofold. First, the debate about which alternative possibilities are robust should be understood as a debate about the kind of abilities the agent has to realise various alternatives. When it is recast in this way, we will see that two things matter: (i) the nature of the alternative the agent can realise (the content of the possible scenario), and (ii) the kind of access the agent has to the said alternative (is the agent able to intentionally realise the alternative, does she have promise-level access to it, etc).

Second, the debate about the Frankfurt-style cases is almost exclusively focused on the robustness of the alternative possibility - i.e. on the kind of ability needed to perform the action which is left unperformed. If I am right that Mele's conjecture is false, then we should not take the account of robustness which these discussions yield - i.e. the account of the ability to perform the alternative action - and treat it also as an account of the ability which is in fact exercised in performing the action actually performed: the two abilities in question need not be the same strength.

This idea that there is an asymmetry in the reliability of powers required for free will has some interesting consequences and deserves more attention. For example, on the plausible assumption that the 'up to us' locution is grounded by the possession of high-reliability abilities, it follows that agents can be responsible for $A$-ing even if their $A$-ing is not up to the agent. Ron, in other words, can be responsible for striking and killing his enemy even though it is false that:

(13) It is up to Ron whether he strikes and kills his enemy.

It would also follow that (13) can be false while (14) can be true:

(14) It is up to Ron whether he refrains from striking his enemy.

There is much more to be said about the similarities among and differences between the multiple kinds of ability which comprise the n-way power required for free will, and the connection between those abilities and the 'up to us' locution (see Shabo 2014 and Kittle 2017 for some initial explorations on the latter topic). I hope in this essay to have made a small contribution towards clarifying the project and so clearing the way for that future discussion. 


\section{References}

Brown, Mark A. 1988. On the Logic of Ability. Journal of Philosophical Logic 17 (1): 1-26.

Fischer, John Martin. 1994. The Metaphysics of Free Will: An Essay on Control. Oxford: Blackwell Publishers.

Frankfurt, Harry G. 1969. Alternate Possibilities and Moral Responsibility. Journal of Philosophy 66 (3): 829-39.

Franzen, Jonathan. 2011. Freedom. London: Fourth Estate.

Hackl, Martin. 1998. On the Semantics of "Ability Attributions".

Horty, John F. 2001. Agency and Deontic Logic: Oxford University Press, USA.

Kane, Robert H. 1996. The Significance of Free Will. New Ed. New York: Oxford University Press, USA.

Kenny, Anthony. 1975. Will, Freedom and Power. Oxford: Blackwell.

Kittle, Simon. n.d. On the Nature of General Abilities. (manuscript)

Kittle, Simon. 2015. Abilities to Do Otherwise. Philosophical Studies 172 (11): 3017-35. https://doi.org/10.1007/s11098-015-0455-8.

Kittle, Simon. 2017. Robustness and up-to-Us-Ness. Disputatio 9 (44): 35-57.

Kittle, Simon. 2018. When Is an Alternative Possibility Robust? European Journal of Philosophy 27 (1): 199-210. https://doi.org/10.1111/ejop.12369.

Kratzer, Angelika. 1977. What 'Must' and 'Can' Must and Can Mean. Linguistics and Philosophy 1 (3): 337-55.

Kratzer, Angelika. 1981. The Notional Category of Modality. In Words, Worlds and Contexts: New Approches in Word Semantics, edited by H. Eikmeyer and R. Rieser. New York: de Gruyter \& Co.

Kratzer, Angelika. 2012. The Notional Category of Modality. In Modals and Conditionals. Oxford,, New York: Oxford University Press.

Mele, Alfred R. 2003. Agents' Abilities. Nô̂s 37 (3): 447-70.

Moya, Carlos. 2011. On the Very Idea of a Robust Alternative. Crítica 43 (128): 3-26.

Papafragou, Anna. 2000. Modality: Issues in the Semantics-Pragmatics Interface. 1st ed. Current research in the semantics/pragmatics interface 6. Amsterdam, New York: Elsevier.

Pereboom, Derk. 2009. Further Thoughts About a Frankfurt-Style Argument. Philosophical Explorations 12 (2): 109-18. https://doi.org/10.1080/13869790902838795.

Portner, Paul. 2009. Modality. Oxford: Oxford University Press.

Shabo, Seth. 2014. It Wasn't up to Jones: Unavoidable Actions and Intensional Contexts in Frankfurt Examples. Philosophical Studies 169 (3): 379-99.

https://doi.org/10.1007/s11098-013-0187-6.

Steward, Helen. 2012. A Metaphysics for Freedom. Oxford: OUP.

van Inwagen, Peter. 1983. An Essay on Free Will. Oxford: Clarendon Press. 
van Inwagen, Peter. 2017. Ability. In Thinking About Free Will, 210-29: Cambridge University Press.

Vetter, Barbara. 2015. Potentiality. Oxford: Oxford University Press.

Vihvelin, Kadri. 2013. Causes, Laws, and Free Will: Why Determinism Doesn't Matter. New York: Oxford University Press.

Widerker, David. 2006. Libertarianism and the Philosophical Significance of Frankfurt Scenarios. Journal of Philosophy 103 (4): 163-87. 